\title{
The Risk of Necrotizing Enterocolitis following the Administration of Hyperosmolar Enteral Medications to Extremely Preterm Infants
}

\author{
Faiza Latheef ${ }^{a, b}$ Hanna Wahlgren ${ }^{a}$ Helene Engstrand Lilja ${ }^{a}$ \\ Barbro Diderholma ${ }^{a}$ Mattias Paulsson ${ }^{a}$

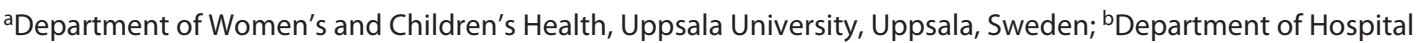 \\ Pharmacy, Region Västmanland, Västerås, Sweden
}

\section{Keywords}

Osmolality - Extremely preterm infant - Oral medication .

Necrotizing enterocolitis · Safety

\begin{abstract}
Introduction: Necrotizing enterocolitis (NEC) is a disease predominantly affecting preterm infants. The administration of hyperosmolar solutions could lead to the development of NEC. The objective of this study was to measure the osmolality of enteral medications used in clinical practice and to assess the risk of NEC following exposure to hyperosmolar medications. Methods: A retrospective cohort study in extremely preterm infants (gestational age $<28$ weeks) born between 2010 and 2016 at a tertiary neonatal intensive care unit in Sweden. 465 infants were identified via the Swedish Neonatal Quality register. Data relating to enteral administrations received during a two-week period were collected from the medical records. The osmolalities of medications were measured using an osmometer. Logistic regression was used to calculate the odds ratio of developing NEC. $\boldsymbol{R e}$ sults: A total of 253 patients met the inclusion criteria. The osmolalities of 5 commonly used medications significantly exceeded the recommended limit of $450 \mathrm{mOsm} / \mathrm{kg}$ set by the American Academy of Paediatrics (AAP). Most patients
\end{abstract}

karger@karger.com www.karger.com/neo

Karger $\stackrel{\text { ' }}{5}$

GOPEN ACCESS
(C) 2021 The Author(s)

Published by S. Karger AG, Basel

This is an Open Access article licensed under the Creative Commons Attribution-NonCommercial-4.0 International License (CC BY-NC) (http://www.karger.com/Services/OpenAccessLicense), applicable to the online version of the article only. Usage and distribution for commercial purposes requires written permission.
(94\%) received at least one hyperosmolar medication. No significant risk of developing NEC could be found. Conclusion: The medications used in clinical practice can significantly exceed the limit set by the AAP. This study does not indicate an increased risk of developing NEC in extremely preterm infants following exposure to hyperosmolar medications. Further studies in larger cohorts are needed to determine the specific cut-off level of osmolality in relation to the pathogenesis of NEC.

(C) 2021 The Author(s)

Published by S. Karger AG, Basel

\section{Introduction}

Necrotizing enterocolitis (NEC) is the most serious gastrointestinal disease affecting neonates. The most significant risk factor that has been associated with NEC is prematurity. The prevalence of NEC in infants with a birth weight of $<1,500$ grams is $10-15 \%$ [1]. Advancements in other fields of neonatal intensive care have led to better survival rates of the most preterm infants, which subsequently has an increased effect on the incidence of NEC $[2,3]$.

Faiza Latheef and Hanna Wahlgren contributed equally to this work.
Faiza Latheef

Department of Hospital Pharmacy Regionhuset

Ingång 4, SE-721 89 Västerås (Sweden) faiza.latheef@regionvastmanland.se 
Despite extensive research, the etiology of NEC is unknown and the pathogenesis is multifactorial [3]. The condition is characterized by intestinal inflammation which can progress to necrosis and intestinal perforation. Other contributing risk factors include enteral feeding, intestinal ischemia, and colonization with pathogenic bacteria [4].

Osmolality refers to the number of particles of solute per kilogram of solvent [5]. The fetal gut is exposed to amniotic fluid (osmolality of $275 \mathrm{mOsm} / \mathrm{kg}$ ) [6,7], and after birth, the gut is exposed to breast milk (osmolality of approximately $300 \mathrm{mOsm} / \mathrm{kg}$ ) [8]. The recommendations, originally set by the American Academy of Paediatrics (AAP) in 1976, state that the osmolality of enteral feeds should not exceed $450 \mathrm{mOsm} / \mathrm{kg}$ [9]. A systematic review conducted by Ellis et al. [10] found no consistent evidence indicating a safety risk following feed hyperosmolality in neonates. White and Harkavy highlighted the potential risk of an increase in osmolality by up to $300 \%$ following the administration of medication to breast milk or formula milk [11].

The objective of this study was to measure the osmolality of enteral medications currently used in clinical practice at a neonatal intensive care unit in Sweden with the aim of assessing the risk of hyperosmolar medications being a contributing factor to the development of NEC in extremely preterm infants.

\section{Materials and Methods}

\section{Patient Cohort}

This study was conducted as a retrospective cohort study of infants treated at a tertiary Neonatal Intensive Care Unit (NICU) at Uppsala University Children's Hospital for a minimum of 14 days during 2010-2016. Inclusion criteria were extremely preterm infants ( $<28$ gestational weeks) born at Uppsala University Hospital or who had been transferred to this hospital within $24 \mathrm{~h}$ after birth. They were identified through the Swedish Neonatal Quality Register (SNQ; www.snq.se). Exclusion criteria were chromosomal abnormalities and congenital heart defects. Patients with incomplete hospital notes and those who died within the first 4 days (considered the minimum length of time required to gather enough relevant data) were also excluded from the study. The study period consisted of the first 14 days of life.

The following data were collected from the medical record system Cambio Cosmic ${ }^{\mathrm{TM}}$ (Cambio, Linköping, Sweden): birth weight and height, gestational age, information on growth restriction and multiple gestations. Patients with NEC were diagnosed by radiological and clinical features by a paediatric surgeon and categorised according to Bell et al.'s [12] criteria. Bell stage $\geq 2 \mathrm{~A}$ was considered a verified NEC-diagnosis.

Data relating to the time, number, and volume of fluid and medication administrations received were collected for all patients from the monitoring systems: Philips IntelliSpace Critical Care \& Anesthesia (ICCA) ${ }^{\mathrm{TM}}$ (Philips, Amsterdam, the Netherlands) and MetaVision ${ }^{\circledR}$ PDMS (IMDSoft, Tel Aviv, Israel) and the medical record system Cambio Cosmic ${ }^{\mathrm{TM}}$. The data were used to estimate the osmolality of each enteral administration that the patients received during the study period. The routine practice at the NICU is for breast milk and oral medications not to be mixed but to be administered consecutively. All infants born before 35 gestational weeks receive mother's own milk or donated breast milk, starting with trophic feeding during the first day of life. The volume of breast milk increases gradually whilst tapering parenteral nutrition and most infants are on full enteral nutrition by days 7-10. Fortification of breast milk usually begins on day 4 . The milk fortifier used during this study period was Pre NAN FM $855^{\circledR}$ (Nestlé). Neonates born under $27+6$ gestational weeks receive fortified milk containing protein to the equivalent of $4 \mathrm{~g} / \mathrm{kg} /$ day with a protein/ energy coefficient of approximately $3.2 \mathrm{~g} / 100 \mathrm{Kcal}$. This is in accordance with guidelines published in 2010 by the European Society for Paediatric Gastroenterology, Hepatology, and Nutrition relating to the feeding of preterm infants [13].

\section{Osmolality Measurements}

The osmolalities of medications were obtained from the Summary of Product Characteristics or were provided from the Medicines Information Department of the manufacturer. Where this information was unavailable, the osmolalities were measured using a VAPRO osmometer 5520 (Wescor Inc., Logan, UT, USA) at the Department of Pharmacy at Uppsala University. The instrument was calibrated using Optimal 290 and 1,000 reference solutions (Wescor Inc., Logan, UT, USA). All measurements were performed in triplicate, and the 2 closest readings used. If the osmolality of the solution exceeded $3,000 \mathrm{mOsm} / \mathrm{kg}$, the solution was diluted at a ratio of 1:3 with distilled water. The samples for each medication were provided by the NICU.

\section{Statistical Analysis}

Categorical variables were described in numbers and frequencies, continuous variables as medians and ranges. The NEC group was divided into those who developed NEC within the study period of 14 days (early onset NEC) and those who developed the disease later (late-onset NEC), and the group was categorized in a similar manner to a previous publication [14]. As data on osmolality in enteral feeds were collected from birth and only 14 days past birth, it was important to divide the group in this manner. Exposure to hyperosmolar solutions after 14 days of life was not considered; however, NEC developing after 14 days was still considered an outcome measure. Differences between groups were analysed with the Mann-Whitney $U$ test. Logistic regression was used to calculate the odds ratio of developing early onset NEC after exposure to hyperosmolar solutions. The risk of NEC was adjusted for birth weight and gestational week at birth. Currently, there is no known "safe" level of osmolality apart from the recommendation of $450 \mathrm{mOsm} / \mathrm{kg}$ set by the AAP, and the analysis was, therefore, repeated using different cut-off levels for hyperosmolality. The following cut-off levels were analysed: $450 \mathrm{mOsm} / \mathrm{kg}, 800 \mathrm{mOsm} / \mathrm{kg}$, and 2,000 mOsm $/ \mathrm{kg}$. The exposure to hyperosmolar solutions was studied in relation to the maximum osmolality received in an enteral administration as well as the cumulative exposure to hyperosmolar solutions received throughout the study period. A $p$ value of $<0.05$ was considered statistically significant. Statistical analyses 
Fig. 1. Flowchart of patients who met inclusion/exclusion criteria for the study population.
465 infants were identified as being born $<28+0$ weeks and treated at Uppsala University Hospital between 2010-2016.

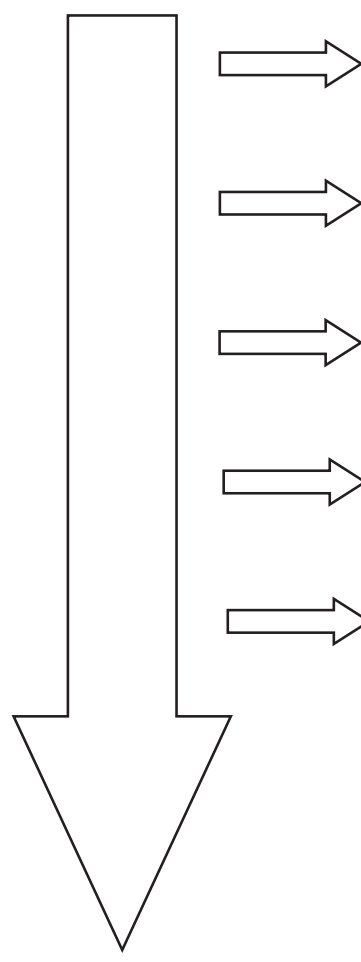

69 infants were excluded as they arrived in Uppsala $>24$ hours after birth.

32 infants were excluded as they died within 4 days from birth.

100 infants were excluded as they moved to other care units within 14 days from birth.

6 infants were excluded as they had chromosomal abnormalities or severe malformations.

5 infants were excluded due to lost data from the relevant period. were performed using R version 3.5.0 (The R Foundation, Vienna, Austria). This study was conducted with ethical approval from the Regional Ethical Review Board in Uppsala, registration number: 2017/193.

\section{Results}

A total of 465 infants were identified through the Swedish Neonatal Quality register and 253 patients that met the inclusion criteria were included in the final cohort as shown in Figure 1. The clinical characteristics of the 253 infants are shown in Table 1. The median gestational age in the entire cohort was 24 weeks and 4 days, and the median birth weight was 650 grams. Most infants (223; 80\%) were born at Uppsala University Hospital. NEC was diagnosed in 47 out of the 253 infants (19\%). Median age at diagnosis was 12 days (range 1-73 days).
The overall mortality in the NEC group was 60\%, compared to $17 \%$ in the non-NEC group.

The osmolality of 5 medications: Alvedon ${ }^{\circledR} 24 \mathrm{mg} / \mathrm{mL}$ paracetamol oral solution (GlaxoSmithKline Consumer Healthcare AB), Paracetamol Apofri ${ }^{\circledR} 24 \mathrm{mg} / \mathrm{mL}$ paracetamol oral solution (Apofri AB), Diflucan ${ }^{\circledR} 40 \mathrm{mg} /$ $m L$ fluconazole oral suspension (Pfizer AB), Koffeincitrat APL $10 \mathrm{mg} / \mathrm{mL}$ caffeine citrate solution (APL AB), and Cvitamin APL $50 \mathrm{mg} / \mathrm{mL}$ ascorbic acid oral solution (APL $\mathrm{AB})$ were unknown and therefore measured. The osmolalities of Addex ${ }^{\circledR}$ Sodium Chloride (NaCl) $4 \mathrm{mmol} / \mathrm{mL}$ concentrate for infusion (Fresenius Kabi AB) [15] and Sodium Bicarbonate $50 \mathrm{mg} / \mathrm{mL}$ solution for infusion (Fresenius Kabi AB) [16]were available in product literature, and the osmolality of Peyona ${ }^{\circledR} 20 \mathrm{mg} / \mathrm{mL}$ caffeine citrate for infusion and oral solution (Chiesi Farmaceutici) was obtained through contact with the manufacturer. 
Table 1. Clinical characteristics of the cohort. The "NEC" group refers to patients who developed NEC (Bell's stage $\geq 2 \mathrm{~A}$ ) at any age. Early onset NEC is defined as a diagnosis of NEC within 14 days of life; late-onset NEC is a diagnosis after 14 days

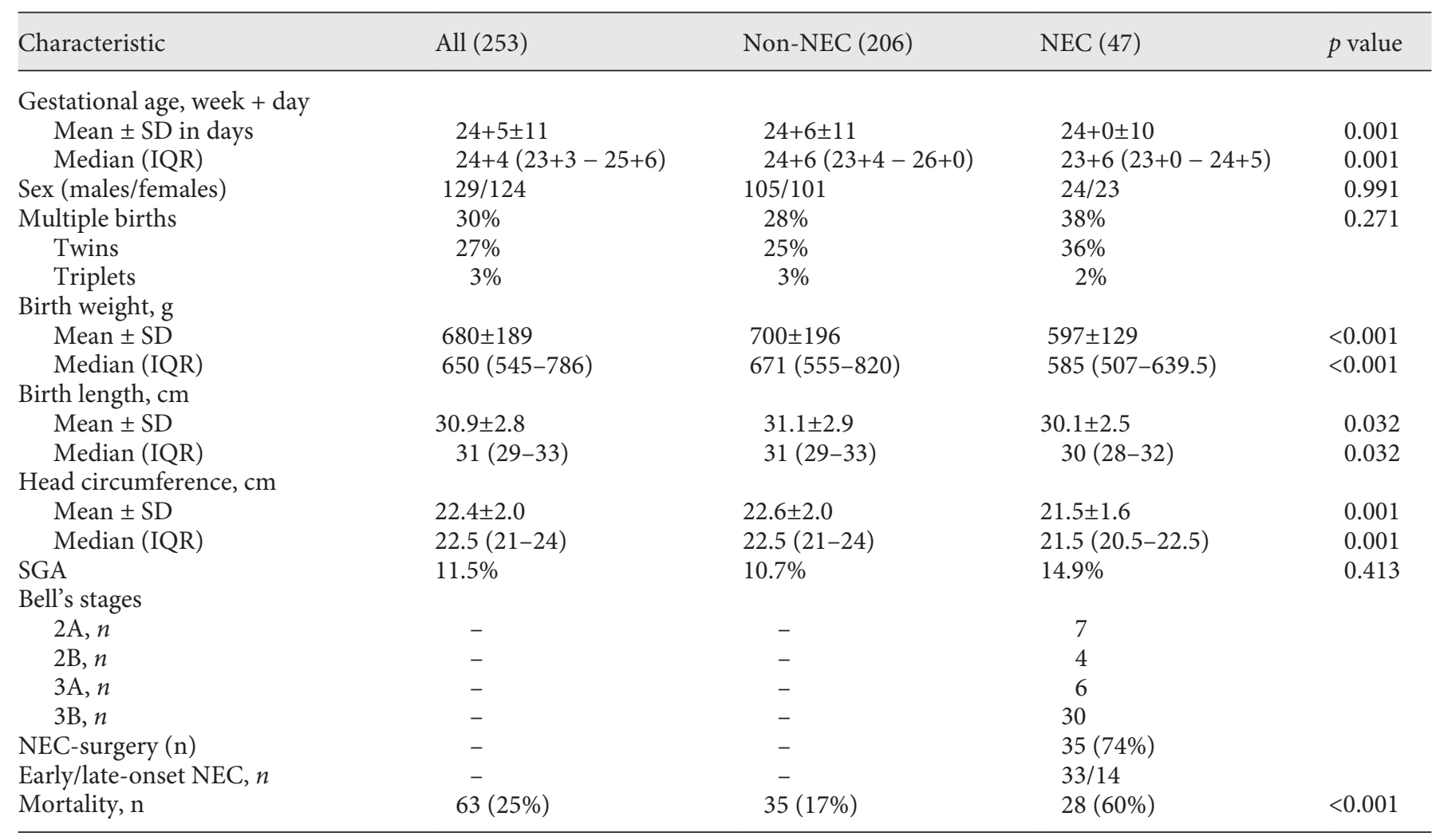

NEC, necrotizing enterocolitis; SGA, small for gestational age; SD, standard deviation; IQR, interquartile range.

Table 2. Osmolalities of the liquid medications administered to the cohort

\begin{tabular}{lc}
\hline Medication & $\mathrm{mOsm} \mathrm{kg}^{-1} \mathrm{H}_{2} \mathrm{O}$ \\
\hline Alvedon $^{\circledR}$ (paracetamol) $24 \mathrm{mg} / \mathrm{mL}$ oral solution & 9,600 \\
Paracetamol Apofri $^{\circledR} 24 \mathrm{mg} / \mathrm{mL}$ oral solution & 9,000 \\
Addex $^{\circledR} \mathrm{NaCl} 4 \mathrm{mmol} / \mathrm{mL}$ concentrate for infusion & 9,000 \\
Diflucan ${ }^{\circledR}$ (fluconazole) $10 \mathrm{mg} / \mathrm{mL}$ powder for oral suspension & 4,500 \\
Sodium bicarbonate $50 \mathrm{mg} / \mathrm{mL}$ solution for infusion & 1,000 \\
Peyona ${ }^{\circledR} 20 \mathrm{mg} / \mathrm{mL}$ for infusion and oral solution & 150 \\
Caffeine citrate APL $10 \mathrm{mg} / \mathrm{mL}$ oral solution & 98 \\
C-vitamin APL 50 mg/mL oral solution & 150 \\
\hline
\end{tabular}

The osmolalities of all the medications are shown in Table 2. The medications that were not considered hyperosmolar were ascorbic acid $50 \mathrm{mg} / \mathrm{mL}$ solution with an osmolality of $150 \mathrm{mOsm} / \mathrm{kg}$ and caffeine citrate (available at 2 different strengths of 10 and $20 \mathrm{mg} / \mathrm{mL}$ ), with an osmolality of 98 and $150 \mathrm{mOsm} / \mathrm{kg}$, respectively.

Most patients (94\%) received at least one of the hyperosmolar medications. There were no significant differences between the groups relating to the frequency of administration of medications as illustrated in Table 3.
The maximum osmolality administered was 9,600 $\mathrm{mOsm} / \mathrm{kg}$ (the osmolality of undiluted oral paracetamol). Administrations of solutions with an osmolality exceeding 9,000 $\mathrm{mOsm} / \mathrm{kg}$ were frequent among patients of all ages.

The odds ratio of developing NEC after receiving solutions with an osmolality exceeding 2,000 $\mathrm{mOsm} / \mathrm{kg}$ was 0.92 . The result was not significant ( $p$ value 0.83 ). The odds ratios for other levels are shown in Table $4 \mathrm{a}$. 
Table 3. Frequency of treatment with hyperosmolar medications in the cohort

\begin{tabular}{|c|c|c|c|c|c|c|}
\hline Sodium chloride (Addex $\left.{ }^{\circledR} \mathrm{NaCl}\right) 4 \mathrm{mmol} / \mathrm{mL}$, concentrate for infusion & $\begin{array}{l}9,600 / 9,000 \\
9,000\end{array}$ & 5 & 5 & 4 & 6 & 0 \\
\hline Fluconazole $\left(\right.$ Diflucan $\left.{ }^{\circledR}\right) 10 \mathrm{mg} / \mathrm{mL}$, powder for oral suspension & 4500 & & & 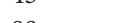 & 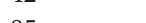 & 50 \\
\hline
\end{tabular}

NEC, necrotizing enterocolitis. ${ }^{1}$ Both formulations were administered interchangeably.

Table 4. Logistic regressions were used to calculate the odds ratio for developing NEC within 14 days at (a) different levels of hyperosmolar administrations received and (b) by cumulative exposure exceeding different cut-off levels of osmolality

\begin{tabular}{|c|c|c|}
\hline $\begin{array}{l}\text { a Highest osmolality received, } \\
\mathrm{mOsm} / \mathrm{kg}\end{array}$ & Odds ratio & $p$ value \\
\hline$>450$ & 0.31 & 0.20 \\
\hline$>800$ & 0.48 & 0.71 \\
\hline$>2,000$ & 0.92 & 0.83 \\
\hline $\begin{array}{l}\text { b Doses received exceeding } \\
\text { osmolality }(\mathrm{mOsm} / \mathrm{kg}), n\end{array}$ & Odds ratio & $p$ value \\
\hline$>450$ & 0.88 & 0.001 \\
\hline$>800$ & 0.96 & 0.51 \\
\hline$>2,000$ & 0.99 & 0.55 \\
\hline
\end{tabular}

The models were adjusted for birth weight (grams) and gestational week at birth.

Another way to measure the exposure to hyperosmolar solutions was to measure cumulative doses administered. The odds ratio for the number of doses exceeding $450 \mathrm{mOsm} / \mathrm{kg}$ was 0.88 , with a $p$ value of 0.001 . Table $4 \mathrm{~b}$ shows the odds ratios in the different levels of osmolality. The results show that this is linked to a lower risk of developing NEC.

\section{Discussion/Conclusion}

This study assessed the risk of developing NEC in extremely preterm infants following administrations of hyperosmolar solutions received during the first 2 weeks of life. The osmolalities of 5 formulations used significantly exceeded the recommended osmolality set by the AAP.
Studies conducted by Jew et al. [17] and Chandran et al. [18] show similar findings.

No statistically significant risk of NEC could be found in this patient cohort. Previous studies have shown varying results. A study done by Book et al. [19] showed a significant increase in the risk of NEC amongst infants receiving formula with an osmolarity of $650 \mathrm{mOsm} / \mathrm{L} \mathrm{com}$ pared to a group of infants receiving formula with an osmolarity of $359 \mathrm{mOsm} / \mathrm{L}$. A similar finding was reported by Theone et al. [20] with a significantly higher incidence of NEC occurring in the group receiving solutions of a higher osmolality. In contrast, other studies did not report a significant difference in the incidence of NEC following the administration of hyperosmolar medications [21-23]. It is often difficult to establish the independent impact of osmolality in various study forms [24]. Furthermore, other factors such as the effect on $\mathrm{pH}$ could be responsible for the fact that an association was found. A systematic review of these studies concluded that randomised controlled trials including $>1,000$ infants would be required to determine effects on key morbidities such as NEC [25].

Diflucan (fluconazole) oral suspension is introduced routinely at our NICU to the preterm infant as prophylactic antifungal treatment. This results in most of the cohort having received a hyperosmolar medication at least once, which diminishes the ability to draw comparisons between the groups. This is reflected in the logistic regression model showing a lower risk of developing NEC following a cumulative exposure to hyperosmolar solutions. Infants who are at risk of developing NEC are managed in the early stages as "Nil by mouth" to rest the bowel and so the cumulative exposure was at times higher in the non-NEC group who continued to receive enteral medications and nutrition. The incidence of NEC in the entire cohort was $10.1 \%$ (47 out of 465 patients) which is com- 
parable to other studies with rates ranging from $2-10 \%$ [3].

Intestinal immaturity seen in preterm infants is a significant risk factor for NEC due to predisposition of the gut to damage. Evidence from animal studies shows that administering continuous hyperosmolar loads to the gastrointestinal tract of newborn rats caused irreversible damage to the intestinal wall aiding the growth of pathogenic bacteria and enabling the movement of micro-organisms to the abdominal cavity [26]. It is important to consider whether dilution down to recommended levels has taken place with the most hyperosmolar oral medications, especially when an infant is not yet on full enteral nutrition (often taking place on day 7-10) as well as when it may be appropriate to administer intravenous medications instead of enteral medications in patients at risk of NEC (see online suppl. material, available at www.karger. $\mathrm{com} / \mathrm{doi} / 10.1159 / 000513169$, for examples of dilutions in this cohort).

Other potential adverse effects relating to hyperosmolar solutions have been identified. These include osmotic diarrhoea, intestinal ischemia, and effects on gastric emptying $[17,27]$. The maximum osmolarity in these studies was $539 \mathrm{mOsm} / \mathrm{L}$ which is significantly less than the osmolalities of the solutions administered in our patient cohort. In a study done by Willis et al. [28], 46\% of the infants showed signs compatible with NEC upon receiving an undiluted calcium lactate supplement with an osmolality of $1,700 \mathrm{mOsm} / \mathrm{kg}$. This study showed a statistically significant reduction in NEC upon dilution of the calcium lactate supplement to an osmolality of $405 \mathrm{mOsm} / \mathrm{kg}$.

The strength of this study is that it highlights the significantly high osmolality of medications used in current practice. Another strength is the relatively large cohort of extremely preterm infants and the amount of data relating to fluid and medication intake that was collected for each individual. A limitation of this study is its retrospective study design and the analysis of pre-existing data assuming that accurate recordkeeping has taken place. This study is prone to selection bias as all infants who were moved to other care facilities within 14 days were excluded. These infants were, on average, more mature, healthier and had a better prognosis for survival. This is reflected by the relatively high incidence (19\%) of NEC in the final cohort of 253 patients.

The osmolality of medications currently used in practice significantly exceed recommended levels. The results of this study do not indicate an increased risk of developing NEC in extremely preterm infants following exposure to hyperosmolar medications. Future studies need to study effects on other factors such as $\mathrm{pH}$ with the aim of pinpointing the independent impact of osmolality on damage to the intestine which thereby may increase the risk of developing NEC.

\section{Acknowledgements}

The authors would like to gratefully acknowledge Cecilia Ewald (NICU, Uppsala) for assistance with the medical records, Dr. Lucia Lazorova (Dept. of Pharmacy, Uppsala University) for support during the osmolality measurements, Per Wikman for guidance in the statistical analysis, Dr. Karl-Johan Lindner (Department of Hospital Pharmacy, Region Västmanland), and Professor Christel Bergström (Department of Pharmacy, Uppsala University) for their valuable contributions and review of the manuscript.

\section{Statement of Ethics}

The Regional Ethical Review Board of Uppsala approved this study on May 17th, 2018, with reference number 2017/193. Complete waiver of consent from patients or in this case, legally authorized representatives, was permitted as this study was conducted as a retrospective study with minimal risk to the patients. The waiver will not adversely affect the rights and welfare of the patients and all data relating to patients are kept anonymized. The authors confirm that this study was conducted in accordance with the Helsinki Declaration as revised in 2013.

\section{Conflict of Interest Statement}

Mattias Paulsson has received honoraria for teaching assignments from the following pharmaceutical companies: Fresenius Kabi, B Braun, and Baxter Medical. Faiza Latheef, Hanna Wahlgren, Helene Engstrand Lilja, and Barbro Diderholm have no conflicts of interest to declare.

\section{Funding Sources}

The Gillberg Foundation and ALF research funds (Government Compensation to County Councils for costs arising from research and education) have contributed to funding this study.

\section{Author Contributions}

Faiza Latheef and Hanna Wahlgren have contributed equally to the article, they have designed the study, collected, and analysed data and written the manuscript. Mattias Paulsson, Barbro Diderholm, and Helene Engstrand Lilja have designed the study and analysed the data. All authors have read and approved the final manuscript.
Latheef/Wahlgren/Lilja/Diderholm/ Paulsson 


\section{References}

1 Lim JC, Golden JM, Ford HR. Pathogenesis of neonatal necrotizing enterocolitis. Pediatr Surg Int. 2015;31(6):509-18.

2 Ahle M, Drott P, Andersson RE. Epidemiology and trends of necrotizing enterocolitis in Sweden: 1987-2009. Pediatrics. 2013;132(2): e443-51.

3 Battersby C, Santhalingam T, Costeloe K, Modi N. Incidence of neonatal necrotising enterocolitis in high-income countries: a systematic review. Arch Dis Child Fetal Neonatal Ed. 2018;103(2):F182-f9.

4 Samuels N, van de Graaf RA, de Jonge RCJ, Reiss IKM, Vermeulen MJ. Risk factors for necrotizing enterocolitis in neonates: a systematic review of prognostic studies. BMC Pediatr. 2017;17(1):105.

5 Ernst JA, Williams JM, Glick MR, Lemons JA. Osmolality of substances used in the intensive care nursery. Pediatrics. 1983;72(3):347-52.

6 Oliveira FR, Barros EG, Magalhães JA. Biochemical profile of amniotic fluid for the assessment of fetal and renal development. Braz J Med Biol Res. 2002;35(2):215-22.

7 Pearson F, Johnson MJ, Leaf AA. Milk osmolality: does it matter? Arch Dis Child Fetal Neonatal Ed. 2013;98(2):F166-9.

8 Rochow N, Fusch G, Choi A, Chessell L, Elliott L, McDonald K, et al. Target fortification of breast milk with fat, protein, and carbohydrates for preterm infants. J Pediatr. 2013; 163(4):1001-7.

9 Barness LA, Mauer AM, Holliday MA, Anderson AS, Dallman PR, Forbes GB, et al. Commentary on breast-feeding and infant formulas, including proposed standards for formulas. Pediatrics. 1976;57(2):278-85.

10 Ellis ZM, Tan HSG, Embleton ND, Sangild PT, van Elburg RM. Milk feed osmolality and adverse events in newborn infants and animals: a systematic review. Arch Dis Child Fetal Neonatal Ed. 2019;104(3):F333-F40.

11 White KC, Harkavy KL. Hypertonic formula resulting from added oral medications. Am J Dis Child. 1982;136(10):931-3.
12 Bell MJ, Ternberg JL, Feigin RD, Keating JP, Marshall R, Barton L, et al. Neonatal necrotizing enterocolitis. Therapeutic decisions based upon clinical staging. Ann Surg. 1978;187(1): $1-7$.

13 Agostoni C, Buonocore G, Carnielli VP, De Curtis M, Darmaun D, Decsi T, et al. Enteral nutrient supply for preterm infants: commentary from the European Society of Paediatric Gastroenterology, Hepatology and Nutrition Committee on Nutrition. J Pediatr Gastroenterol Nutr. 2010;50(1):85-91.

14 Yee WH, Soraisham AS, Shah VS, Aziz K, Yoon W, Lee SK. Incidence and timing of presentation of necrotizing enterocolitis in preterm infants. Pediatrics. 2012;129(2):e298304.

15 Addex Sodium Chloride SmPC [internet]. 2010. Available from: https://www.lakemedelsverket.se/sv/sok-lakemedelsfakta/ lakemedel id $=19660112000046 \&$ type $=$ prod uct.

16 Sodium bicarbonate SmPC [internet]. 2012. Available from: https://docetp.mpa.se/LMF/ Natriumbikarbonat $\% 20$ Fresenius $\% 20$ Kabi\%2050\%20mg\%20ml\%20sol\%20f\%20 inf\%20SmPC_09001bee807a49d7.pdf.

17 Jew RK, Owen D, Kaufman D, Balmer D. Osmolality of commonly used medications and formulas in the neonatal intensive care unit. Nutr Clin Pract. 1997;12(4):158-63.

18 Chandran S, Chua MC, Lin W, Min Wong J, Saffari SE, Rajadurai VS. Medications that increase osmolality and compromise the safety of enteral feeding in preterm infants. Neonatology. 2017;111(4):309-16.

19 Book LS, Herbst JJ, Atherton SO, Jung AL. Necrotizing enterocolitis in low-birth-weight infants fed an elemental formula. J Pediatr. 1975;87(4):602-5.
20 Thoene M, Lyden E, Weishaar K, Elliott E, Wu R, White K, et al. Comparison of a powdered, acidified liquid, and non-acidified liquid human milk fortifier on clinical outcomes in premature infants. Nutrients. 2016;8(8): 451.

21 Kim JH, Chan G, Schanler R, Groh-Wargo S, Bloom B, Dimmit R, et al. Growth and tolerance of preterm infants fed a new extensively hydrolyzed liquid human milk fortifier. J Pediatr Gastroenterol Nutr. 2015;61(6):665-71.

22 Rigo J, Hascoët JM, Billeaud C, Picaud JC, Mosca F, Rubio A, et al. Growth and nutritional biomarkers of preterm infants fed a new powdered human milk fortifier: a randomized trial. J Pediatr Gastroenterol Nutr. 2017;65(4):e83-93.

23 Singh P, Thakur A, Dogra S, Garg P, Srivastav LM, Kler N. Comparison of osmolality of human milk after fortification with three different fortifiers. Curr Med Res Pract. 2017;7(3): 81-3.

24 Miyake H, Chen Y, Koike Y, Hock A, Li B, Lee $\mathrm{C}$, et al. Osmolality of enteral formula and severity of experimental necrotizing enterocolitis. Pediatr Surg Int. 2016;32(12):1153-6.

25 Ellis ZM, Tan HSG, Embleton ND, Sangild PT, van Elburg RM. Milk feed osmolality and adverse events in newborn infants and animals: a systematic review. Arch Dis Child Fetal Neonatal Ed. 2019;104(3):F333-f40.

26 Feigenberg Z, Levavi H, Abramovici A. Effect of a hyperosmolar solution on the small intestine of newborn rats: irreversible damage and overgrowth of bacteria. Pediatr Surg Int. 1993;8(6):488-90.

27 Pascale JA, Mims LC, Greenberg MG, Alexander JB. Gastric response in low birth weight infants fed various formulas. Biol Neonate. 1978;34(3-4):150-4.

28 Willis DM, Chabot J, Radde IC, Chance GW. Unsuspected hyperosmolality of oral solutions contributing to necrotizing enterocolitis in very-low-birth-weight infants. Pediatrics. 1977;60(4):535-8. 